\title{
DAS UTOPIAS À REALIDADE: É POSSÍVEL UMA DIDÁTICA ESPECIFICA OU ESPECIAL PARA A FORMAÇÃO INICIAL DO PROFESSOR DE EDUCAÇÃO ARTÍSTICA?
}

\author{
DE LAS UTOPÍAS A LA REALIDAD: ¿ES POSIBLE UNA DIDÁCTICA ESPECÍFICA O ESPECIAL PARA LA \\ FORMACIÓN INICIAL DEL PROFESOR DE EDUCACIÓN ARTÍSTICA?
}

\author{
FROM UTOPIA TO REALITY: IS IT POSSIBLE A SPECIFIC OR SPECIAL TEACHING FOR TEACHERS \\ TRAINING IN ART EDUCATION?
}

\author{
DR. FÁBIO JOSÉ RODRIGUES DA COSTA \\ fajorodrigues@uol.com.br \\ Escola de Artes Reitora Violeta Arraes Gervaiseau \\ Universidade Regional do Cariri - URCA
}

\begin{abstract}
Baseado na Tese "Didáctica de las Artes Visuales: una proposición posmoderna" defendida no Programa de Doutorado em Educación Artística: enseñanza y aprendizaje de las Artes Visuales - Universidad de Sevilla - España e subvencionada pelo Conselho Nacional de Desenvolvimento Científico e Tecnológico $\mathrm{CNPq} /$ Brasil.
\end{abstract}

Artigo apresentado no Congresso Ibero-Americano de Educação Artística: Sentido Transiberico - Beja/Portugal/2008.

Artigo Original

\section{RESUMO}

Este artigo surge da tese "Didática das Artes Visuais: uma proposição pós-moderna" desenvolvida no Programa de Doutorado em Educação Artística da Universidade de Sevilla - Espanha. A pesquisa teve como objetivo principal sistematizar uma didática especifica para o currículo de formação inicial do curso de Licenciatura em Artes Visuais para o contexto brasileiro. No âmbito metodológico foi orientado pela concepção de pesquisa qualitativa em educação e definiu-se por um estudo de caso tanto por se tratar de uma perspectiva para a Educação Superior brasileira quanto por ter tomado como objeto de estudo a Proposta Triangular e o Curso de Aperfeiçoamento em Aprendizagem da Arte e Cultura Contemporânea ambos idealizados por Ana Mae Barbosa. O trabalho de campo foi realizado em São Paulo e contou com entrevista narrativa, análise de conteúdo e história de vida enquanto instrumentos de coleta de dados selecionados uma vez que se pretendia reconstruir a experiência vivida pelos sujeitos sociais da pesquisa e a partir de suas contribuições estabelecer um paralelo entre esta experiência com as exigências contemporâneas no campo das Didáticas Específicas. A análise e interpretação dos dados foram orientadas por meio da Análise Biográfico-Narrativa. No âmbito epistemológico a pesquisa se fundamenta na teoria pós-moderna e sua imbricação com a educação e a educação artística ou 
arte/educação. Esta teoria parte do conceito de mudança de Paulo Freire e Joe Kincheloe que consideram que a pós-modernidade exige uma reconceitualização do conhecimento do professor e o concebe como um pesquisador provocando uma recontextualização de sua formação inicial.

\section{RESUMEN}

El articulo surge de la tesis “Didactica de las Artes Visuales: una proposición posmoderna" desarrollada en el Programa de Doctorado en Educación Artística: enseñanza y aprendizaje de las artes visuales de la Universidad de Sevilla - España. La investigación tuvo como objetivo principal sistematizar una didáctica específica para el curriculum de formación inicial de la Carrera de Licenciado en Artes Visuales para el contexto brasileño. En el ámbito metodológico fue orientado por una concepción de investigación cualitativa en educación y se definio por un estudio de caso tanto por se tratar de una perspectiva para la Educación Superior brasileña cuanto por tener tomado como objeto de estudio la Proposta Triangular y el Curso de Perfeccionamiento en Aprendizaje del Arte y Cultura Contemporánea ambos idealizados por Ana Mae Barbosa. El trabajo de campo fue realizado en São Paulo y conto con entrevista narrativa, analisis de contenido e historia de vida en cuanto instrumento de coleta de datos, seleccionados una vez que se pretendía reconstruir la experiencia vivida por los sujetos sociales de la investigación y a partir de sus contribuciones establecer un paralelo entre esta experiencia con las exigencias contemporáneas en el campo de las Didácticas Especiales. El analisis e interpretación de los datos fue orientado por medio del Analisis Biografico-Narrativo. En el ambito epistemologico la investigación se fundamenta en la teoría posmoderna y su imbricación con la educación y la educación artística o arte/educación. Esta teoría parte del concepto de cambio de Paulo Freire y Joe Kincheloe que consideran que la posmodernidad exige una reconceptualización del conocimiento del profesor y le concibe como uno investigador provocando una recontextualización de su formación inicial.

\section{ABSTRACT}

This article is based on the PhD thesis : 'Didactics of Visual Arts, a post-modern suggestion $* *$ submitted to the University of Sevilla , Spain. The research aims were the design of a specific curriculum for university visual art courses in the Brazilian context. The research method was quantitative, being a case-study focused on Ana Mae Barbosa rationale: 'Proposta Triangular' and in her postgraduate Course Learning Art and Contemporary Culture. The field work was in São Paulo and integrated research instruments such as open interviews, content analysis and biographical narratives as the objective was to reconstruct life experiences of the respondents in order to compare them with contemporary need in Specific Didactics. As for the epistemology of the research the approach followed post-modern theories in education and art education, such approach starts from Paulo Freire's and Joe Kincheloe concept of change considering that 
post-modern times require a reconceptualization of the role of teacher that may be seen as a researcher and consequentially needs a change in its knowledge base and initial training.

PALAVRAS-CHAVE: Pós-modernidade. Didáticas específicas. Educação artística. Resignificação. Reconceitualização.

PALABRAS-LLAVE: Posmodernidad. Didácticas Específicas. Educación Artística. Resignificación. Reconceptualización.

KEY WORDS: Postmodernity, Specific Didactics, Art Education, Reframing, Reconceptualization

\section{INTRODUÇÃo}

As idéias presentes neste texto objetivam atender as expectativas expressadas pelos organizadores do Primeiro Congresso Ibero-Americano de Educação Artística. Digo primeiro porque vejo que estaremos muito em breve nos reencontrando para dar continuidade ao que se supõe será o percurso natural desta iniciativa.

Outro aspecto que no momento considero importante diz respeito ao fato de que meus argumentos não estão postos como verdade, ou melhor, como a única verdade. Minha narrativa nasce das preocupações que estão ainda na pauta do dia quando nos perguntamos sobre a formação inicial do professor para a área de Educação Artística nos mais diferentes contextos culturais o que significa que a formação de professores não é privilegio de uma determinada sociedade e/ou cultura, mas sim que em tempos contemporâneos ainda se reconhece a importância deste profissional da cultura e para a cultura (Giroux, 1999).

Para mediar a leitura que cada um fará deste texto e que poderá servir como subsídio as discussões nos grupos de trabalho, não posso deixar de contextualizar sua "Genesis", ou seja, como vão tomando corpo minhas próprias indagações nascidas das contradições que acredito ainda permeiem a formação inicial do professor da área de Educação Artística.

Responder aos questionamentos que foram sendo levantados necessitou a formulação de um projeto de pesquisa que hoje se materializou na tese de doutorado intitulada Didáctica de las Artes Visuales: una proposición posmoderna (Didática das Artes Visuais: uma proposição pósmoderna) defendida em junho de 2007 na Universidade de Sevilla - Espanha.

A pesquisa buscou dialogar com três importantes campos do conhecimento que constituem a formação inicial do professor e à luz da teoria pós-moderna crítica permitiu trabalhar com a categoria Resignificação. Esta categoria orientou a identificação dos elementos (re) significadores para a formação inicial do professor, a didática geral e as didáticas específicas e a partir desses elementos foi possível conceitualizar e sistematizar uma Didática Especifica para a formação inicial de professores para a linguagem das Artes Visuais tomando como proposição a Proposta Triangular formulada e amplamente experimentada pela Prof $\stackrel{\text { a }}{\text { Dr }}$. Ana Mae Barbosa para o contexto brasileiro.

Esta didática foi tecida tendo como eixo norteador a leitura da imagem, a alfabetização visual para a leitura da imagem, a partir da concepção de alfabetização como leitura de mundo segundo Paulo Freire.

No entanto, a Didática das Artes Visuais, como a concebo, não se propõe dizer ao professor como ele deve ensinar, mas sim, com ele conhece, aprende e compreende as pedagogias contemporâneas e seus modelos educativos para a alfabetização visual ou para a decodificação das 
visualidades do tempo presente. É no currículo da licenciatura em Artes Visuais ou similares que se dá a inserção dessa didática o que impõe a (re) conceitualização dos currículos destinados a formação inicial do professor.

Deste modo esta proposição se orientou em primeiro lugar pela compreensão de que a pós-modernidade está a (re) conceitualizar e (re) significar a formação inicial do professor de artes visuais ou educação artística já que no mundo considerado global há outras formas de compreendê-lo e uma destas é a metodologia centrada nos aspectos culturais que busca explicar o eu e o outro em seu próprio contexto, porém buscando a relacionalidade como modo operante da teoria pós-moderna (Chang, 2003).

Esta relacionalidade orienta-se pelo princípio de perten$c ̧ a$, de pertencer a um lugar, um grupo, uma comunidade, um país, um gênero e ao mesmo tempo pertencer a todos. Isso porque no contexto atual homem/mulher caminha em direção a encontrar sua própria identidade não guiada por uma epistemologia de verdade única moderna e, sim, por sua própria necessidade de respostas à sua condição humana.

Assim as contribuições da teoria pós-moderna estabelecem outras relações entre o passado e o presente, entre o tempo e o espaço, entre o homem/mulher de antes e o homem/mulher de hoje em exercício constante de leitura que impõe a compreensão crítica da realidade ao mesmo tempo em que supõe sua denúncia (Freire, 2001). Deste modo esta pós-modernidade tenta abrir caminhos em direção a outra forma de organização humana, do saber, da educação, de formação inicial do professor, de escola e de ensino e aprendizagem.

As contribuições da teoria pós-moderna para a arte e seu ensino começam pela compreensão da arte como um conhecimento implicado no mundo rompendo com o isolamento característico da modernidade. Ao mesmo tempo em que a arte na pós-modernidade busca conectar-se com o público de forma interdisciplinar e pela exposição de temáticas que se aproximam da cotidianidade (Gisbert, 2002).
Neste sentido, a arte na pós-modernidade é um produto cultural devendo ser entendida no contexto onde teve origem e recepção (Efland, 2003) e que reflete o retorno ao real, ao tempo presente (Gisbert, 2002).

\section{Elementos (Re) significadores da Formação Inicial do Professor de Artes Visuais ou Educação Artística no Contexto da Pós-Modernidade}

Parto do conceito de mudança a partir das idéias de Paulo Freire e Joe Kincheloe (2001) que consideram que a pós-modernidade exige uma (re) conceptualização do conhecimento do professor como ponto de partida já que esta começa pela aceitação do professor como pesquisador e, que a partir desta perspectiva se (re) contextualiza a formação inicial do professorado tendo nos pressupostos da pesquisa qualitativa suas principais ferramentas com uma forte inclinação para os estudos etnográficos e semióticos.

Propõe uma ruptura com os modelos modernos de formação inicial do professor por considerar que estes oferecem uma formação tecnicista que está fechada a argumentação. Considera, portanto, que a formação inicial do professor está centrada fundamentalmente na experimentação que se aproxima do pensamento de Dewey (2004) e de seu sentido de "experiência reflexiva" promovida pelo pensar como um processo de indagação, de observação das coisas, de investigação.

Ao mesmo tempo em que parte de uma educação pósmoderna e de uma perspectiva de formação inicial do professor de forma crítica e pós-formal e que por intermédio desta formação se desconstrói a concepção de ensino como uma transferência neutra da verdade (Kincheloe, 2001). O pensamento pós-formal se ocupa da desconstrução da forma absolutista de certeza já que o pensamento pós-formal atento para o uso dado a cognição pela educação contemporânea identifica duas formas distintas de tratá-la. Em uma, se detecta uma concepção de educação que se dedica a manipulação da cognição e outra uma educação para o desenvolvimento cognitivo ou emancipatório (Kincheloe, 2001). 
Elementos (Re) significadores da Didática Geral e das Didáticas Específicas no Contexto da Pós-Modernidade

No âmbito da Didática Geral e das Didáticas Específicas a cognição é compreendida para além do essencialismo cognitivo que caracteriza a educação moderna e adere aos estudos críticos como a teoria sociocognitiva póspiagetiana com bases no pensamento pós-formal e na teoria feminista.

Esta (re) significação estabelece a crítica ao essencialismo e ao reducionismo que orientam a Didática Geral e Instrumental moderna inspirada na psicologia do desenvolvimento, a favor de um desenvolvimento cognitivo que não se constitui de uma dimensão estática e inata do ser humano.

A Didática Geral orientada pela teoria sociocognitiva póspiagetiana vislumbra uma ação educativa crítica e centrada nos múltiplos saberes, nos múltiplos lugares e tempos em que o conhecimento tem origem e se desenvolve e os utiliza para analisar a formação inicial contemporânea do professor.

A Didática Geral se (re) significa a partir da incorporação de novas temáticas vinculadas diretamente com o ensino enquanto uma prática social concreta e tem no Multiculturalismo Crítico (McLaren, 2000) uma base teórica que a explica e a justifica em plena contemporaneidade (Candau, 2001) já que tem a cultura como categoria central de análise uma vez que a cultura é dinâmica, se reinventa e (re) significa as instituições e seu papel na formação humana.

O processo de (re) significação da Didática Geral reconhece sua natureza incompleta, portanto, encontra nas Didáticas Específicas contribuições que a complementam ou tentam (de la Torre, 1993). A Didática Específica não substitui a Didática Geral, porém estabelece conexões que ampliam, principalmente, a formação inicial do professor e busca estabelecer relações diretas com a ação educativa deste profissional da cultura na escola com a perspectiva de (re) conceitualizar os conteúdos de ensino que se ca- racterizam como conteúdos educativos, instrumentais e operativos (Souza, 2004).

A construção das Didáticas Específicas resulta imprescindível para o professor que se ocupa de uma determinada disciplina (Gallego, 2002) e seu papel na formação do sujeito a partir do Projeto Educativo e Curricular de um determinado contexto de ensino/aprendizagem (Zabalza, 2001).

A incorporação da Didática Específica passa por uma (re) conceitualização da estrutura curricular das universidades que em sua maioria não renunciam a um tipo de formação inicial do professor formulada por uma educação moderna (Zabalza, 2001).

\section{A Proposta Triangular no Contexto da Pós-Moderni- dade e a Formação Inicial do Professor de Artes Visu- ais ou Educação Artística}

Os pressupostos teórico/filosóficos que fundamentam a Proposta Triangular tornam esta proposição uma referência para a formação inicial do professor de Artes Visuais ou Educação Artística para além do contexto brasileiro porque parte de uma visão interdisciplinar e contextual do fenômeno artístico, do artefato artístico e do sujeito que o produz como dimensões de um ensino e formação inicial do professor exigida pela inter-relação como categoria mediadora das diferentes culturas, dos fatores ambientais e da relação com outros grupos sociais (Gisbert, 1993).

A Proposta Triangular recebe influências do pós-modernismo entendido como um fenômeno estético, cultural e intelectual que se manifesta concretamente nos estilos, práticas e formas culturais nas artes visuais contemporâneas (Hagreaves, 1998).

Inserida no contexto da pós-modernidade e de seu movimento cultural, a Proposta Triangular reconhece que o conhecimento em artes visuais se dá na intersecção da experimentação, da decodificação e da informação uma vez que a Arte/Educação ou Educação Artística é epistemologia da arte como pressuposto e como meio de inter- 
relação ente arte e público, ou seja, a intermediação entre o objeto arte e o público (Barbosa, 1998).

Neste sentido, nem a Arte/Educação ou Educação Artística como pesquisa dos modos pelos quais se aprende arte, nem a Arte/Educação ou Educação Artística como facilitadora entre a arte e o público podem prescindir da inter-relação entre contextualização da arte, leitura da obra de arte e das imagens do cotidiano e do fazer artístico, segundo Barbosa (1998).

A arte na escola pretende formar o conhecedor, o decodificador da obra de arte e das imagens do cotidiano ou da cultura visual. A ação educativa do professor deve organizar o currículo entrelaçando o fazer artístico, a contextualização da arte/imagem e a leitura de forma que sejam respeitados tanto as necessidades, interesses e desenvolvimento da criança como oferecendo ao próprio ensino outros valores de forma a contribuir para a cultura (Barbosa, 2001).

A Proposta Triangular vislumbra um campo de formação inicial do professor de artes visuais ou educação artística em que teoria e prática se fundem em um todo e por esta razão é imprescindível a experimentação caminhando lado a lado com os pressupostos teóricos e metodológicos. Neste sentido, a educação cultural é o que pretende esta proposição pós-moderna a partir de uma educação crítica do conhecimento construído pelo aluno, com a mediação do professor, acerca do mundo da cultura visual (Barbosa, 1998) a partir de uma leitura do mundo como prática da liberdade (Freire, 1970).

\section{Da (Re) conceitualização ao Lócus de Formação Ini- cial do Professor de Artes Visuais ou Educação Artís- tica no Contexto da Pós-Modernidade}

Compreendendo que a formação inicial do professor faz parte do sistema de educação superior das sociedades contemporâneas, e que cada uma delas guarda especificidades, os elementos (re) significadores abrem espaço para uma releitura do lugar de formação do professor na contemporaneidade brasileira, ou seja: a) Define a licenciatura como o campo de formação inicial do professor na educação superior;

b) Considera a formação inicial do professor como preparação profissional e que esta preparação passa a ter um papel importante no contexto contemporâneo que possibilita aos professores experimentarem em sua própria aprendizagem, o desenvolvimento de competências necessárias para atuar neste novo cenário de transformações;

c) Toma para si o conceito de experiência a partir do pragmatismo deweyano e amplia consideravelmente o próprio sentido de formação inicial do professor já que a ela se acrescenta não só o conceito, mas sua dimensão educativa e formativa mais ampla que é exatamente o fato de que o aluno-professor em formação chega a estabelecer as relações e conexões tanto dentro de seu próprio processo de aprendizagem como a partir de seu encontro com as situações geradas nos momentos de por em prática suas primeiras iniciativas como docente na escola;

d) Compreende o sentido da experiência no processo de formação inicial do professor mediada pela leitura do mundo como proposto por Paulo Freire;

e) Define no âmbito institucional o lugar para a formação inicial do professor e que se ocupe dos problemas e especificidades das diferentes etapas e modalidades da educação básica, estabelecendo o equilíbrio entre o domínio dos conteúdos curriculares e sua adequação a situação pedagógica;

f) Define a licenciatura como o lugar da docência onde se constrói competências e se configura a identidade profissional do professor em geral e, em específico, para o ensino das artes visuais ou educação artística;

g) Assume como eixo da matriz curricular que a ação educativa não é só histórica, filosófica, educativa e pedagógica e, sim que é disciplinar e interdisciplinar.

\section{CONCLUSÃO}

A conclusão a que chego neste texto não é definitiva porque o exercício que nos propomos a vivenciar deverá ofe- 
recer novas contribuições, no entanto, a mesma pode ser compreendida como um exercício de resposta a pergunta formulada a partir do titulo proposto, ou seja: É possível uma didática especifica ou especial para a formação inicial do professor de educação artística? Me apoio neste momento nas idéias e categorias sistematizadas por Gallego (2002) para definir os elementos que deve conter e constituir toda e qualquer didática específica e, no caso específico deste texto, a didática das artes visuais.

Categoria organizada do conhecimento: se constituiu no âmbito da didática das artes visuais pelas aproximações as pedagogias contemporâneas e seus modelos educativos que objetivam desde a alfabetização visual a educação para a experiência estética, além disso, no processo de formação inicial do professor gera outras possibilidades de desenvolvimento de modos de ensinar e aprender artes visuais;

1. Constitui-se em um campo emergente e que levará seu tempo para que seja acolhida pela própria problemática que caracteriza a área da Arte/Educação ou Educação Artística que não tem incorporado estudos e pesquisas que ultrapassem os territórios do como se aprende, para o território do como se ensina/aprende artes visuais no contexto da educação básica e na universidade;

2. A didática das artes visuais como uma comunidade de conhecimento surge da constatação de problemas nas concepções de formação inicial do professor, porém que seu enfoque principal é o porquê e o como se podem superar os imaginários que limitam a formação de identidades (Aguirre, 2006) já que se ocupa na busca por superar o ideário modernista de ensino/aprendizagem das artes visuais, ainda, centrada na auto-expressão criativa, na obra de arte como o "refinamento" e o "bom gosto" caracterizadores do neoclassicismo;

3. A didática das artes visuais no contexto da formação inicial do professor busca desenvolver uma concepção do currículo como pluridisciplinar, aberto a emergência, crítico e não reprodutivo, portanto, centrado nos significados e na preparação de pesso- as para desenvolver-se em contextos cada vez mais dominados pelo visual (Aguirre, 2006);

4. A didática das artes visuais deve dedicar-se a partir de uma concepção interdisciplinar do problema atual do ensino das artes visuais no contexto da educação como área do conhecimento para a escola e o processo de ensino/aprendizagem do professor para ensinar arte (artes visuais) nesta escola a partir de uma concepção que supere o modernismo e dê lugar ao pós-modernismo que considera a arte como experiência (Barbosa, 2005);

5. Os fundamentos de Paulo Freire (2004) são acolhidos pela didática das artes visuais já que em seus esforços por explicar e interpretar a realidade parte da compreensão de que a educação deve entenderse como a construção de identidades (Giroux, 1997; Aguirre, 2006);

6. Explicar e interpretar a realidade é para a didática das artes visuais identificar os limites que apresenta o currículo atual para a formação inicial do professor e o papel das instituições formadoras e, ao mesmo tempo, a própria didática se ver como objeto de explicação e interpretação da realidade por esta inserida como disciplina do processo formativo levado a diante pelas instituições formadoras e sua imbricação com a educação básica;

7. A didática das artes visuais apresenta como categoria o significado e suas vinculações sociais uma vez que as disciplinas e matérias escolares foram se construindo ao largo da história da educação escolar, e a formação inicial do professor deste modo se ocupa do significado e suas vinculações sociais em relação ao que ocorre na escola de educação básica a partir do que ensinam os professores, buscando estabelecer relações entre ela, à matéria escolar, os professores, a escola, a universidade e as relações de poder que cada uma representa (Goodson, 2000);

8. O imaginário se constitui em outra categoria da didática das artes visuais que maneja com os imaginários constituidores do perfil do professor moder- 
nista e busca o desenvolvimento de um imaginário pós-modernista onde este perfil revele um professor reflexivo, crítico, sujeito implicado e que dialoga com a realidade, que compreende que sua ação educativa está envolvida nas dimensões sócio-críticas e integrada em contextos ideológicos, que busca desenvolver uma compreensão crítica do fenômeno artístico e que, além disso, se vê mediado pela cultura e as instituições culturais;

9. A didática das artes visuais inserida no pós-modernismo e na pós-modernidade apresenta léxicos como as palavras que constituem um repertório de significados, o que supera a dimensão semântica que normalmente se exige de uma comunidade de conhecimento, pois considera que os termos que usa para descobrir-se a si mesma e as coisas estão sempre sujeitos a mudanças (Aguirre, 2006);

10. A didática das artes visuais como uma comunidade de conhecimento se identifica no âmbito metodológico pela ação-reflexão-ação como possibilidade de aproximação a realidade com a intenção de na práxis social compreender os processos, significados e interpretações que as pedagogias contemporâneas e seus modelos educativos propõem para a formação inicial do professor de artes visuais e o ensino/ aprendizagem que colocará em movimento considerando esta formação e ação educativa mediada pela experiência como reorganizadora e renovadora de outras experiências (Dewey, 2004; Freire, 2001).

Com base no exposto, este texto finaliza suas contribuições com a compreensão de que no contexto da pós-modernidade e do pós-modernismo a proposição da Didática das Artes Visuais resultou em uma aproximação à educação como uma constante reorganização das experiências humanas (Gisbert, 1994), onde sua mais sensível crença reside no fato de que toda atividade humana começa na observação. Do mesmo modo, a aprendizagem ou construção de novos conhecimentos começa com a observação de acontecimentos, objetos ou idéias a partir dos conceitos prévios que possuímos. 0 ensino tratará, portanto, de construir a trama estrutural do conhecimento a partir das proposições que formam os conceitos e estes, por sua vez, o significado (Gisbert, 1994).

\section{BIBLIOGRAFIA}

AGUIRRE, Imanol. (2006) "Hacia un imaginario para el futuro en educación artística”, Actas Digitales del I Congreso Internacional de Educación Artística y Visual. Sevilla: Ilustre Colegio Oficial de Doctores y Licenciados en Bellas Artes de Andalucía,

. (2005) Teorías y Prácticas en Educación Artística, Barcelona: Octaedro,

BARBOSA, Ana Mae (2005) A imagem no ensino da arte, São Paulo: Perspectiva, 2001

Arte/Educação Contemporânea: consonâncias internacionais, São Paulo: Cortez,

lo: Cortez . (2001). John Dewey e o Ensino da Arte no Brasil, São Pau-

(2001). Tópicos Utópicos, Belo Horizonte: C/Arte, 1998.

CANDAU, Vera Maria. (2001) A didática em questão, Petrópolis: Vozes,

CHANG, Elaine K. (1993) “El cruce de fronteras: Feminismo, posmodernismo y subjetividad fugitiva”. En: MICHAELSEN, Scott y JOHNSON, David E. Teoria de la Frontera: los límites de la política cultural, Barcelona: Gedisa, 2003

DE LA TORRE, Saturnino. Didáctica y Currículo: Bases y componentes del proceso formativo, Madrid: Dykinson,

DEWEY, John. (2004.) Democracia y educación, Madrid: Morata,

. (2003). Experiencia y educación, Madrid: Biblioteca Nueva,

EFLAND, Arthur D. (2004). La educación en el arte posmoderno, Barcelona: Paidós Ibérica,

FREIRE, Paulo. (2001). Pedagogía de la indignación, Madrid: Morata, (2001). Pedagogía do Oprimido, Rio de Janeiro: Paz e Terra,

GALLEGO, Isidoro G. 2002 "Las didácticas de área: un reciente campo científico", Educación, 328, pp. 11-34,.

GIROUX, Henry A. (1999). Cruzando as Fronteiras do Discurso Educacional, Porto Alegre: ArtMed,

(1997) Cruzando límites: trabajadores culturales y políticas educativas, Barcelona: Paidós Ibérica.

GISBERT, Juan Carlos A. (1994). "Arte, Educación y Creatividad", PIXELBIT. Revista de Medios y Educación, http://www.sav.us.es/pixelbit/ pixelbit.htm

(2002) "Cibermodernidad o la educación artística de Pokemon", Arte, Individuo y Sociedad, Anejo, pp. 187-194,

GOODSON, Ivor F. El Cambio en el Curriculum, Barcelona: Octaedro, 2000. 
HARGREAVES, A. (1998) Profesorado, cultura y postmodernidad: cambian los tiempos, cambia el profesorado, Madrid: Ediciones Morata.

KINCHELOE, Joe L. (2001) Hacia una revisión crítica del pensamiento docente, Barcelona: Octaedro.

MCLAREN, Peter. (2000) Multiculturalismo Revolucionário: Pedagogia do dissenso para o novo milênio, Porto Alegre: Artes Médicas Sul.

SOUZA, João Francisco de. (2004) E a educação: ¿¿quê?? a educação na sociedade e/ou a sociedade na educação, Recife: Bagaço.

ZABALZA, Miguel Angel (2001). “El sentido de las Didácticas Específicas en las Ciencias de la Educación”. En: PERALES, F. Javier, GARCÍA, Antonio Luis, RIVERA, Enrique, BERNAL, Julia, MAESO, Francisco, MUROS, Jesús, RICO, Luis, ROLDÁN, Joaquín (eds.) Actas del I Congreso Nacional de Didácticas Específicas, Granada: Grupo Editorial Universitario, pp. 25-46. 